\title{
An iterative regularization method for variational inequalities in Hilbert spaces
}

\author{
Hong-Kun Xu, Najla Altwaijry and Souhail ChebBi
}

\begin{abstract}
.
We consider an iterative method for regularization of a variational inequality (VI) defined by a Lipschitz continuous monotone operator in the case where the set of feasible solutions is decomposed to the intersection of finitely many closed convex subsets of a Hilbert space. We prove the strong convergence of the sequence generated by our algorithm. It seems that this is the first time in the literature to handle iterative solution of ill-posed VIs in the domain decomposition case.
\end{abstract}

Acknowledgment. The authors extend their appreciation to the Deanship of Scientific Research at King Saud University for funding this work through research group no. (RG-1440-058).

\section{REFERENCES}

[1] Altwaijry, N., Aldhaban, T., Chebbi, S. and Xu, H. K., Krasnoselskii-Mann viscosity approximation method for nonexpansive mappings, Mathematics, 8 (2020), 1153

[2] Bakushinskii, A. B., Methods for solving monotonic variational inequalities, based on the principle of iterative regularization, U.S.S.R. Comput. Maths. Math. Phys., 17 (1978), 12-24

[3] Bauschke, H., The appoximation of fixed points of compositions of nonexpansive mappings in Hilbert space, J. Math. Anal. Appl., 202 (1996), 150-159

[4] Konnov, I. V. and Schaible, S., Duality for equilibrium problems under generalized monotonicity, J. Optim. Theory Appl., 104 (2000), 395-408

[5] Krjanev, A. V., An iterative method for solving incorrectly posed problems, USSR Comput. Math. Math. Physics, 14 (1974), 24-35

[6] Krjanev, A. V., The solution of incorrectly posed problems by methods of successive approximations, Soviet Math. Doklady, 14 (1973), 673-676

[7] Li, F., Liang, J. and Xu, H. K., Existence of mild solutions for fractional integrodifferential equations of Sobolev type with nonlocal conditions, J. Math. Anal. Appl., 391 (2012), 510-525

[8] Martinez, Y. and Dinh, A. P. N., A generalization of Tikhionov's regularizations of zero and first order, Comp. Maths. Appl., 12B (1986), 1203-1208

[9] O'Hara, J. G., Pillay, P. and Xu, H. K., Iterative approaches to convex minimization problems, Numer. Funct. Anal. Optim., 25 (2004), 531-546

[10] O'Hara, J. G., Pillay, P. and Xu, H. K., Iterative approaches to convex feasibility problems in Banach spaces, Nonlinear Anal., Theory, Methods, Appl., 64 (2006), 2022-2042

[11] Reich, S. and Xu, H. K., An iterative approach to a constrained least squares problem, Abstract Applied Anal., 8 (2003), 503-512

[12] Wang, F. and Xu, H. K., Cyclic algorithms for split feasibility problems in Hilbert Spaces, Nonlinear Anal. Theory, Methods Appl., 74 (2011), 4015-4111

[13] Xu, H. K., Iterative algorithms for nonlinear operators, J. London Math. Soc., 66 (2002), 240-256

Received: 30.07.2020; In revised form: 17.08.2020; Accepted: 17.08.2020

2010 Mathematics Subject Classification. 47J20, 47J25, 47H09.

Key words and phrases. monotone operator, variational inequality, projection, iterative method.

Corresponding author: Najla Altwaijry; najla@ksu.edu.sa 
[14] $\mathrm{Xu}, \mathrm{X}$. and $\mathrm{Xu}, \mathrm{H}$. K., Regularization and iterative Methods for monotone variational inequalities, Fixed Point Theory Appl., Vol. 2010, Article ID 765206, 11 pages.

[15] Yao, Y., Chen, R. and Xu, H. K., Schemes for finding minimum-norm solutions of variational inequalities, Nonlinear Anal., Theory, Methods, Appl., 72 (2010), 3447-3456

DEPARTMENT OF MATHEMATICS

HANGZHOU DIANZI UNIVERSITY

SCHOOL OF SCIENCE

HANGZHOU 310018, CHINA

Email address: xuhk@hdu.edu.cn

DEPARTMENT OF MATHEMATICS

KING SAUd UNIVERSITY

COllege OF SCIENCE

P.O. BOX 2455, RIYADH 11451, SAUdi ARABIA

Email address: najla@ksu.edu.sa

Email address: schebbi@ksu.edu.sa 